\title{
Comunidades de hongos actinomicetos en tres tipos de vegetación de la Amazonia colombiana: abundancia, morfotipos y el gen 16s ADNr
}

\author{
Gladys Inés Cardona ${ }^{1}$, Clara Patricia Peña-Venegas ${ }^{1} \&$ Manuel Ruiz-García ${ }^{2}$ \\ 1. Instituto Amazonico de Investigaciones Científicas-SINCHI, Calle 20 No. 5-44 Bogota DC, Colombia; \\ gcardona@sinchi.org.co \\ 2. Laboratorio de Genética de Poblaciones Molecular y Biología Evolutiva. Departamento de Biología, Facultad de \\ Ciencias, Pontificia Universidad Javeriana. Cra 7A No 43-82, Bogota DC, Colombia; mruiz@javeriana.edu.co
}

Recibido 15-IV-2008. Corregido 14-VI-2009. Aceptado 14-VII-2009.

\begin{abstract}
Communities of Actynomicetes fungy in three vegetation types of the Colombian Amazon: abundance, morphotypes and the 16s rDNA gene. Among soil microorganisms, Actinomycetes play an important role in the sustainability of natural and agricultural systems: decomposition of organic matter; degradation of recalcitrant compounds like lignin; nitrogen fixation; degradation of agricultural chemicals and biological control in plants and animals. We evaluated their diversity in soils under three different vegetation covers (pasture, tropical primary forest and stubble) at two depths in the Southern Colombian Amazon border. We collected five replicates per vegetation type (in each, three samples at $0-20 \mathrm{~cm}$ and three at $20-30 \mathrm{~cm}$; for a total of 30 samples). Abundance and phenotypic diversity were determined by plate counting. Genomic DNA was extracted from the isolates: the 16s rDNA gene was amplified with specific primers, and its genetic diversity was estimated by means of an amplified restriction analysis (ARDRA). Actynomicetes abundance varied with vegetation and depth, possibly reflecting presence of earthworms, macro-fauna and physico-chemical characteristics associated to fertility, as well as organic matter, total bases, and optimal capacity to cationic interchange. Primary forests had the highest diversity. Sixteen morpho-types (six genera) were identified; Streptomyces was the most abundant everywhere. The heterogeneity of ARDRA patterns prevented species identification because of the intra-species variability in sequences of $16 \mathrm{~s}$ rDNA operons. This community is a biological indicator of landscape alteration and could include new bio-active compounds of pharmaceutical interest. Rev. Biol. Trop. 57 (4): 1119-1139. Epub 2009 December 01.
\end{abstract}

Keys words: Actynomicetes, pasture, tropical primary forest, stubble, 16S rDNA gen, ARDRA, phenotype and genetic diversity, Colombian Amazon.

En el sur del trapecio de la Amazonía colombiana se observan procesos de "colonización" basados en modelos occidentales de producción, con agricultura intensiva (cultivos de bajo rendimiento) y desarrollo de una ganadería incipiente en paisajes no aptos para este uso (IGAC 1997). Esta intervención ha tenido como principales consecuencias la disminución de especies forestales, de especies animales, el aumento de los procesos erosivos del suelo y su consecuente degradación, la escasez de productos derivados del bosque y un gran desequilibrio ecológico inherente a la misma fragilidad del ecosistema (IGAC 1996).

El sistema selvático tropical es considerado como el más grande de los sistemas vivientes, ya que alberga un número incalculable de especies diversas, a pesar de que cubre sólo el $10 \%$ de la superficie del planeta. De este modo, el Amazonas constituye el punto neurálgico de la biodiversidad en la Tierra. La cantidad de organismos que alberga es enorme. Se estima que más de la mitad de toda la biodiversidad del planeta se encuentra en esta región del 
trópico sudamericano. Se ha considerado un mínimo de dos millones de especies en esta región, aunque este valor probablemente represente una subestimación considerable (Vanderlei Anselmi 2004).

El Amazonas almacena el 8\% del dióxido de carbono de la biosfera y del $20 \%$ del ciclo del agua dulce en el planeta. De gran importancia es el papel que cumplen los microorganismos del suelo, del agua y del aire. Se han realizado numerosos estudios a cerca de la fauna y flora de los ecosistemas amazónicos (Ruiz-García et al. 2007) pero, sin embargo, a pesar del conocimiento que se posee de la biodiversidad amazónica, resulta evidente que falta avanzar mucho en el entendimiento de su enorme complejidad. Esta afirmación es especialmente cierta en el caso de la vida microbiana (Borneman \& Triplett 1997).

Entre los microorganismos del suelo, los actinomicetos son uno de los grupos de bacterias más abundantes $(90 \%)$, mostrando actividad biodegradativa al secretar un amplio rango de enzimas que les permiten metabolizar moléculas recalcitrantes. También exhiben diferentes estrategias, desde ciclos de rápida proliferación y esporulación, hasta el mantenimiento de poblaciones por prolongados periodos de tiempo. Esta versatilidad metabólica y morfológica les confiere un gran potencial para desempeñarse en procesos de biorremediación, incluyendo la remoción de metales (Albarracín et al. 2005). De igual manera, desempeñan un rol crucial en la sostenibilidad a largo plazo de los sistemas naturales y agrícolas, debido al papel que cumplen en la descomposición de la materia orgánica, fijación de nitrógeno (Frankia sp.), degradación de agroquímicos y el control biológico de plagas de plantas y animales (Williams et al. 1984).

Una de sus características más importantes es su capacidad para producir antibióticos (Heuer et al. 1997), enzimas y productos bioactivos. Boudemagh et al. (2005) mencionan que los actinomicetos representan la principal fuente de metabolitos secundarios con actividad anticelular. Las especies pertenecientes al género Streptomyces constituyen el $75 \%$ del total de la población con capacidad para producir moléculas con actividad antibiótica.

Al formar parte del sistema de descomposición de la materia orgánica, los actinomicetos pueden ser indicadores de fertilidad y servir como elemento de aproximación a la dinámica de un ecosistema, teniendo en cuenta que su funcionamiento, antes y después de un proceso de perturbación, está influenciado por las poblaciones microbianas edáficas (Kennedy \& Smith 1995).

El estudio de actinomicetos ha sido llevado a cabo tradicionalmente mediante técnicas de cultivo dependiente (recuentos en placa de cultivo). Hiltner \& Störmen (1903) (citado en Waksman 1967) fueron los primeros en cuantificar este grupo en el suelo, encontrando que representan cerca del 13 al 30\% de los microorganismos. Posteriormente, Conn et al. (1996) (citado en Waksman 1967) reportaron que los actinomicetos representan más del $40 \%$ de la comunidad en suelos ricos en raíces y, aproximadamente, el $21 \%$ en suelos cultivados.

$\mathrm{Xu}$ et al. (1996) estudiaron la diversidad y las características biológicas de actinomicetos acuáticos en 12 lagos del "Middle Plateau" de Yunnan en China, aislando 60 géneros diferentes, siendo Micromonospora el más dominante, seguido por Streptomyces. Correlacionado con esto, Hua-Li et al. (1996), también, estimaron la diversidad de actinomicetos en suelos de la misma región china por medio del aislamiento y enumeración en medios de cultivo de enriquecimiento. Reportaron una mayor diversidad en suelos bajo bosque primario, seguida por suelos bajo bosque secundario y, finalmente, por granjas cultivadas con vegetales. El género Streptomyces fue el más importante, representando el $90 \%$ de la diversidad total.

Sin embargo, a pesar de la importancia de estos procesos funcionales, son muy escasos los trabajos realizados en la Amazonía colombiana sobre la diversidad de este grupo $\mathrm{y}$, en especial, sobre la influencia que ejerce la modificación de la cobertura vegetal natural sobre la estructura de esta comunidad microbiana. El primer trabajo realizado para este territorio fue llevado a cabo por De La Torre 
(1993), en el Departamento de Caquetá. Allí se estudió la distribución y caracterización de las poblaciones microbiológicas en los suelos del bosque húmedo tropical, reportando que la comunidad microbiana está representada en un $65 \%$ por bacterias, un 25 a $30 \%$ por hongos y de un 2 a un 14\% por actinomicetos. También en territorio colombiano, Corredor (2000) evaluó la estructura de las comunidades edáficas de Streptomyces en seis coberturas vegetales en la franja cafetera del Quindío (Andes colombianos), por métodos microbiológicos tradicionales y moleculares. Un tercer trabajo, éste en el área amazónica, fue el de Cardona et al. (2005), que evaluaron la diversidad del género Streptomyces en suelos bajo bosques y potreros en un área de colonización del municipio de San José de Guaviare, reportando una mayor diversidad del género en suelos bajo bosque.

Los objetivos prioritarios del presente estudio fueron los siguientes: 1- Determinar la posible diferenciación significativa en la abundancia de actinomicetos en suelos bajo bosques, pastos y rastrojos en el sur del trapecio amazónico colombiano. 2- Estimar la existencia de posible heterogeneidad significativa en la abundancia de actinomicetos entre los diferentes puntos de muestreo dentro de una misma cobertura. 3- Establecer posibles diferencias significativas en la abundancia de actinomicetos a diferentes profundidades de muestreo en las tres coberturas analizadas. 4- Identificar diferentes morfotipos de actinomicetos a partir de características macro y microscópicas en las diversas muestras y coberturas analizadas. 5Estimar posibles diferencias significativas en el número de morfotipos de actinomicetos entre cada una de las coberturas estudiadas. 6- Determinar la posible relación de las características físico-químicas del suelo con la abundancia de actinomicetos en las coberturas muestreadas y 7- Establecer las relaciones genéticas entre los 16 morfotipos de actinomicetos encontrados mediante la aplicación de 8 enzimas de restricción al amplificado del gen ADNr 16s.

\section{MATERIALES Y MÉTODOS}

El trabajo de campo se realizó en los municipios de Leticia (comunidades de Macedonia, San Martín de Amacayacu, Mocagua, Santa Sofía, Vergel y Zaragoza) en el Departamento de Amazonas, habitados por comunidades de las etnias Ticuna y Yagua (Fig. 1). Se analizaron tres tipos de cobertura vegetal: bosques secundarios sin intervención durante por lo menos los últimos treinta (30) años, pastizales de diez (10) y treinta (30) años con ganadería semi-extensiva, y rastrojos de seis (6) y ocho (8) años (tiempo transcurrido en su recuperación natural, luego de la tala del bosque natural, cambio de cobertura, uso y abandono del lugar).

Las muestras de suelo se colectaron siguiendo un diseño de muestreo sistemático (Corredor 2000), analizando cinco repeticiones por tipo de cobertura para un total de 15 unidades experimentales. Se tomaron séis muestras compuestas en cada unidad experimental; 3 muestras entre 0 y $20 \mathrm{~cm}$ de profundidad y las otras tres entre 20 y $30 \mathrm{~cm}$, para un total de 30 muestras. Para la caracterización físicoquímica se tomó una muestra compuesta en cada unidad experimental, teniendo un total de 15 muestras.

Se tomaron aproximadamente 1000 gramos de suelo de los cuales $200 \mathrm{~g}$ se usaron para el cultivo dependiente y $500 \mathrm{~g}$ para el análisis físico-químico. Las muestras se guardaron en una bolsa plástica de 1lb., debidamente identificadas y se conservaron en nevera de icopor con hielo seco hasta su envío al laboratorio. A cada muestra se le asignó un código de identificación, con el que se describió el tipo de cobertura, y el número del sitio. Con las letras B, P y R se designaron las coberturas (bosque, pastizal y rastrojo, respectivamente) y con los números romanos I, II, III, IV y V se identificó cada uno de lo sitios.

Adicionalmente, se registró un conjunto de observaciones de campo: coordenadas 


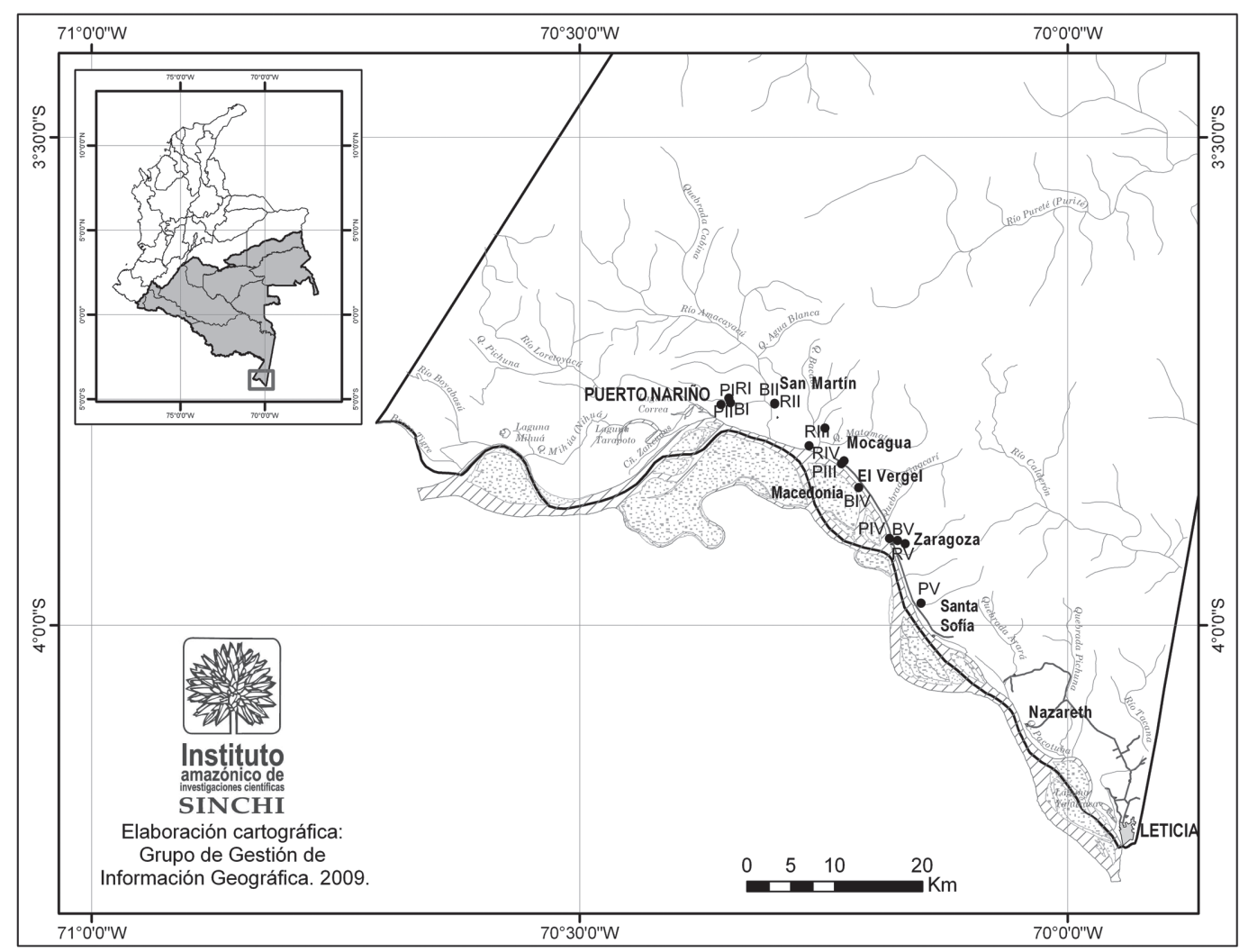

Fig. 1. Área general de muestreo-sur del trapecio amazónico colombiano.

Fig. 1. General area sampled. Southern Colombian Amazon.

geográficas (latitud y longitud) mediante el sistema de posicionamiento global por satélite (GPS), edad de la cobertura, espesor del horizonte orgánico, presencia de lombrices, maraña de raíces y actividad de macrofauna. Para la cobertura pastizal se registró el género o especies de pasto que se encontraban establecidos, tiempo de uso en ganadería, número de cabezas de ganado, número de hectáreas en pasto, presencia de otras especies vegetales y prácticas de cultivo, y para los rastrojos se tuvo en cuenta las especies sembradas después de la quema y algunos problemas fitosanitarios durante el manejo de la chagra.

Abundancia de actinomicetos e identificación de morfotipos: Se estimó la abundancia de actinomicetos por medio del conteo de unidades formadoras de colonia (UFC) en el medio de cultivo almidón amoniacal (AA) $(\mathrm{pH}$ 5.5): almidón de papa $10 \mathrm{~g} / \mathrm{L} ; \mathrm{K}_{2} \mathrm{HPO}_{4} 1 \mathrm{~g} / \mathrm{L}$; $\left(\mathrm{NH}_{4}\right) \mathrm{SO}_{4} 2 \mathrm{~g} / \mathrm{L} ; \mathrm{MgSO}_{4} 0.5 \mathrm{~g} / \mathrm{L} ; \mathrm{KCl} 0.5 \mathrm{~g} / \mathrm{L}$; $\mathrm{FeSO}_{4} 0.01 \mathrm{~g} / \mathrm{L}$ y Agar $12 \mathrm{~g} / \mathrm{L}$. Reportado por Goodfellow \& Williams (1983) como un medio que favorece la recuperación de diferentes géneros de actinomicetos.

Se aislaron por siembra en placa de cultivo, preparando para cada muestra una serie de diluciones entre $10^{-2}$ y $10^{-4}$ de la siguiente manera: de las muestras refrigeradas se tomaron $10 \mathrm{~g}$ de suelo y se diluyeron en $90 \mathrm{ml}$ de agua peptonada al $1.0 \%$. De esta dilución se tomó una alícuota de $1 \mathrm{ml}$ y se diluyó en $9 \mathrm{ml}$ de agua peptonada para obtener la dilución 
$10^{-2}$. Este procedimiento se repitió consecutivamente hasta obtener la dilución $10^{-4}$. En cada caja de petri con el medio de cultivo (AA) se sembró en superficie $0.1 \mathrm{ml}$ del inóculo de la dilución $10^{-4}$. Las muestras se sembraron por triplicado y se incubaron a $28^{\circ} \mathrm{C}$ por $8-15$ días.

Después del periodo de incubación se determinó el número de UFC para cada muestra. Asimismo, se identificaron los diferentes morfotipos teniendo en cuenta características macroscópicas de la colonia, como coloración del micelio aéreo y del sustrato, superficie, forma y tamaño, presencia o ausencia de halos de transparencia y producción de pigmentos. Para la identificación de géneros se tuvo en cuenta características microscópicas observadas por coloraciones de Gram y Zielh-Nielsen, como fragmentación del micelio en formas cocoides, bacilares o artroconidiales, presencia de espirales y bucles, formación de esporangios, presencia de esporas terminales, en pares o grupos en el micelio. A partir de los aislamientos primarios se hicieron repiques en AA de cada uno de los morfotipos descritos. Los cultivos se incubaron en posición invertida por un periodo de $8-10$ días a $28^{\circ} \mathrm{C}$.

Caracterización físico-química del suelo: Los análisis fueron realizados por el laboratorio de suelos del Instituto Geográfico Agustín Codazzi (IGAC). Se realizó el análisis químico Q-01. Los parámetros evaluados fueron textura, CIC (capacidad de intercambio catiónico), Calcio, Magnesio, Potasio, Fósforo, Aluminio de cambio, saturación de bases, carbón orgánico y $\mathrm{pH}$.

Extracción de ADN de las colonias: Para la extracción del ADN de cada uno de los morfotipos, se siguió el protocolo de microextracción de ADN genómico diseñado por Corredor (2000). El aislamiento del ADN se realizó a partir de aproximadamente $50 \mathrm{mg}$ de micelio o esporas obtenidas del cultivo puro. El producto final se resuspendió en $50 \mu 1$ de buffer TrisHCl-EDTA: TE (10:1). El ADN se cuantificó por fluorometría a una longitud de onda de $365 \mathrm{~nm}$.
Amplificación del gen ADNr 16s a partir de los aislamientos: A partir del ADN obtenido, se amplificó el gen ADNr 16S por PCR usando cebadores específicos para el grupo filogenético de los actinomicetos. La selección de los cebadores para la amplificación específica del gen de interés se realizó siguiendo el trabajo de Heuer et al. (1997), en el que se reporta la utilización del primer F243 como específico para la amplificación del gen $16 \mathrm{~S} \mathrm{ADNr}$ de actinomicetos en combinación con el primer R513GC, el cual es homólogo a un dominio conservado universalmente y que debido a una base A en el extremo terminal 3' preferencialmente anilla a secuencias blanco en bacterias gram positivas y B-proteobacteria.

Se utilizó $4 \mu 1$ del ADN genómico como plantilla para la amplificación por PCR y agua tipo HPLC fue usada como control negativo. La amplificación fue llevada a cabo en $46 \mu \mathrm{l}$ de volumen de reacción, usando los primers: 243 Forward (5 '-GGATGAGCCCGCGGCCTA-3') y 513 GC Reverse (5'-Gc-CGGCCGCGGCTGCTGGCACGTA-3'). Las amplificaciones se llevaron a cabo en un termociclador $\mathrm{MJ}$ Research PTC-100. Los productos de PCR se separaron en geles de agarosa al $1 \%$, se colorearon con bromuro de etidio $(0.5 \mathrm{mg} / \mathrm{mL})$ y se visualizaron bajo una fuente de luz ultravioleta. Las imágenes fueron captadas y digitalizadas en un equipo Gel Doc 100 de Bio-Rad conectado a un computador, mediante el software Molecular Analyst (Versión 1.5 Bio-Rad).

Ensayos de análisis de restricción de ADN ribosomal amplificado (ARDRA): El ADN amplificado fue digerido con $5 \mathrm{U}$ de ocho enzimas de restricción, siendo éstas HhaI, HinfI, MspI, HaeIII, AluI, AvaI, RsaI y TaqI, según las condiciones del fabricante, en el buffer de reacción apropiado y en un volumen final de $20 \mu 1$. Los productos de restricción se separaron en geles de agarosa de MetaPhor (Cambrex)-Agarosa ultrapura (Invitrogen) en proporción 2:1 a una concentración del $2.7 \%$ en buffer TBE 0.5X. La electroforesis se llevó a cabo a $110 \mathrm{~V} / 60 \mathrm{~mA}$ por $2.5 \mathrm{~h}$, incluyendo como marcador de peso de 100pb (Ready Load 
ladder Invitrogen). Los geles se tiñeron con bromuro de etidio $(0.5 \mathrm{mg} / \mathrm{mL})$ y se visualizaron bajo una fuente de luz ultravioleta. Las imágenes fueron captadas y digitalizadas en un equipo Gel Doc 100 de Bio-Rad conectado a un computador, mediante el software Molecular Analyst (Versión 1.5 Bio-Rad)

A partir del número de UFC de actinomicetos en cada muestra de suelo se determinó su abundancia con base a la ecuación:

\section{Abundancia $=$ UFC. $*$ factor de dilución $\left(10^{4}\right)$}

Con la abundancia relativa de los diferentes morfotipos se determinó, mediante la herramienta Biotools de Excel (Microsoft 1997), la diversidad fenotípica de actinomicetos con base en los índices de diversidad de Shannon (1948) (H'), índice de equitatividad de Hill (1973) (E), índice de riqueza de Margalef (1972) (R1) e índice de dominancia de Simpson (1949) (D) (Magurran 1988).

El análisis de varianza (ANOVA) y las pruebas de comparación múltiple (prueba de Tukey (Tukey 1953); prueba de NewmanKeuls (Newman 1939, Keuls 1952); prueba de Duncan (Duncan 1955); prueba de Scheffé (Scheffé 1959)), llevadas a cabo para determinar la existencia de diferencias significativas entre coberturas, muestras y profundidades, se realizaron mediante el programa $\mathrm{R}$ versión 1.7 corriendo en el sistema operativo Windows.

Para determinar la relación entre la abundancia de actinomicetos y los diversos morfotipos encontrados respecto a las características fisico-químicas de los suelos examinados se empleó un análisis canónico de correspondencias (ACC). Este análisis es apropiado para representar tablas de frecuencias (Cuadras 1991). El mismo permite la representación simultánea de abundancias y morfotipos de actinomicetos respecto a las características fisico-químicas determinadas en los suelos con la representación de abundancias y morfotipos diferenciados por la distancia ji-cuadrado, al igual que la diferenciación con esta distancia para las características fisico-químicas de los suelos. Para determinar qué factores son significativos se aplicó la prueba de independencia completa (Cuadras 1991), el método de la descomposición aditiva de la ji-cuadrado (Williams 1952) y los procedimientos de Cordier (1965), Benzecrí (1976) y Lleonart (1978). Este análisis fue llevado a cabo mediante el paquete estadístico PC-ORD desarrollado para el análisis estadístico de datos ecológicos.

Para el análisis de relación genética entre los morfotipos de actinomicetos, se interpretaron los patrones generados por ARDRA como un conjunto de caracteres binarios, en donde la presencia de la banda (1) es uno de los estados del carácter y la ausencia (0) el otro. Con base en los resultados moleculares, se construyó una matriz binaria a la que se le aplicó el índice de similitud de Dice (Zuart 1998) equivalente a la distancia de Nei-Li (Nei 1987) y construyendo un fenograma con el algoritmo "Unweighted Pair Group Method with Arithmeric mean" (UPGMA) con el programa NTSYS versión 2.0 (Rohlf 1998).

\section{RESULTADOS}

Abundancia de Actinomicetos en las tres coberturas evaluadas: Como se observa en la Fig. 2, la abundancia varió entre las tres coberturas vegetales. Las pruebas de comparaciones múltiples para los promedios de abundancia de las tres coberturas con los test de Tukey, Newman-Keuls, Duncan y Scheffé reflejaron diferencias significativas entre las coberturas bosque y pasto $(\mathrm{p}<0.05)$ y entre las coberturas bosque y rastrojo $(\mathrm{p}<0.01)$. Sin embargo, las diferencias entre las coberturas pastizal y rastrojo no son tan claras porque algunas pruebas de comparaciones múltiples revelaron diferencias significativas entre estas dos coberturas (Newman-Keuls y Duncan) pero otras no (Tukey y Scheffé).

Se encontraron diferencias en los promedios de abundancia entre los sitios muestreados en la cobertura de bosque, encontrándose un valor mayor en el sitio de muestreo BV (Cuadro 1). Igualmente, se evidenciaron diferencias en la abundancia de actinomicetos entre los diferentes sitios de muestreo bajo pastizal y 
Abundancia de Actinomicetos en las tres coberturas evaluadas

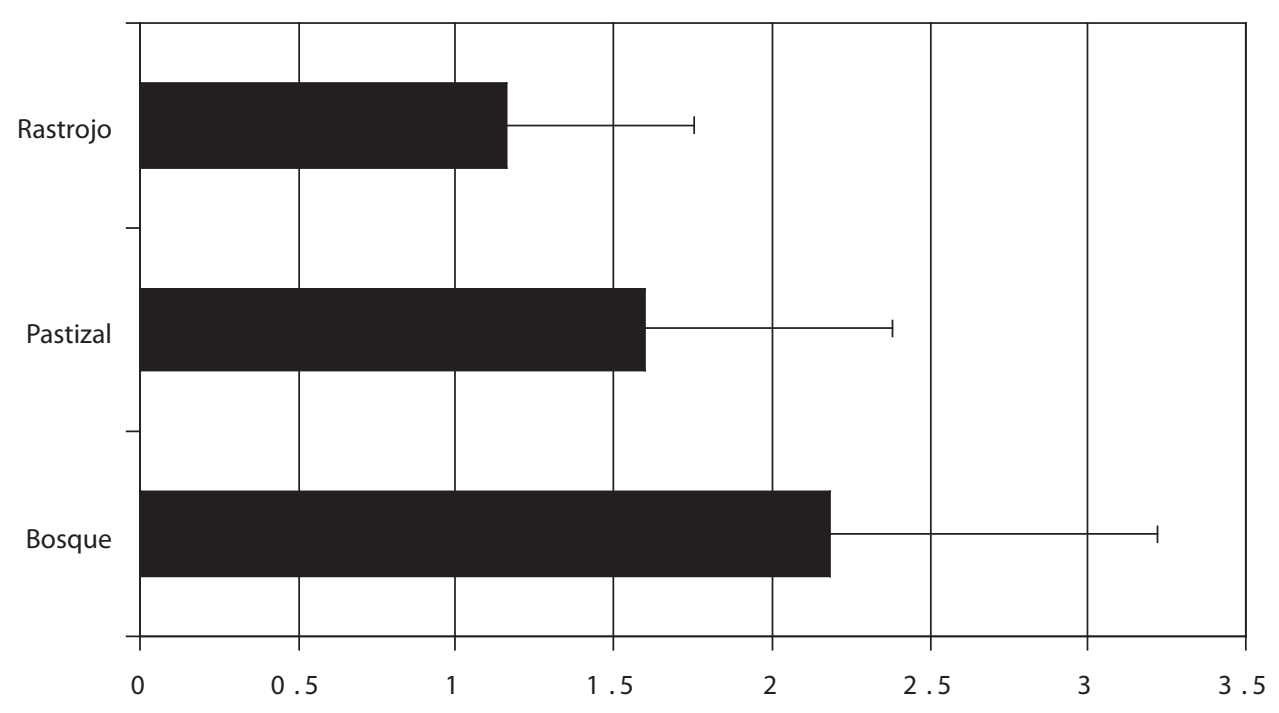

Fig. 2. Abundancia de actinomicetos ( \pm desviación estándar) en suelos bajo bosque, pasto y rastrojo.

Fig. 2. Abundance of Actynomicetes ( \pm standard deviation) in soils under stubble, pasture and tropical primary forest covers.

\section{CUADRO 1}

Abundancia de actinomicetos ( \pm desviación estándar) en células por gramo de suelo, en los diferentes sitios de muestreo con la cobertura bosque

TABLE 1

Abundance of Actynomicetes ( \pm standard deviation) in cells per gram of soil, in different sampling sites with the tropical primary forest cover

$\begin{array}{cc}\text { Cobertura Bosque } & \text { Abundancia } \times 10^{4}(\mathrm{UFC} / \mathrm{g}) \\ \text { BI } & 1.88 \pm 0.88 \\ \text { BII } & 2.22 \pm 0.69 \\ \text { BIII } & 0.57 \pm 0.07 \\ \text { BIV } & 2.6 \pm 0.86 \\ \text { BV } & 3.27 \pm 0.83\end{array}$

rastrojo (Cuadros 2 y 3), siendo las réplicas II y I las que reportaron los mayores promedios de abundancia de actinomicetos, respectivamente.

Abundancia de Actinomicetos en las dos profundidades del suelo estudiadas: Se llevaron a cabo pruebas de comparaciones múltiples para los promedios de UFC de las interacciones

\section{CUADRO 2}

Abundancia de actinomicetos ( \pm desviación estándar) en células por gramo de suelo, en los diferentes sitios de muestreo con la cobertura pastizal

\section{TABLE 2}

Abundance of Actynomicetes ( + standard deviation) in cells per gram of soil, in different sampling sites with the pasture cover

\begin{tabular}{cc} 
Cobertura Pastizal & Abundancia x $10^{4}$ (U.F.C/g) \\
\hline PI & $0.54 \pm 0.24$ \\
PII & $2.67 \pm 1.05$ \\
PIII & $1.37 \pm 1.29$ \\
PIV & $1.43 \pm 0.71$ \\
PV & $1.87 \pm 0.89$
\end{tabular}

cobertura por profundidad utilizando el método de la diferencia significativa honesta de Tukey. Se observó que no existen diferencias significativas en la abundancia de actinomicetos ( $\mathrm{P}>0.05)$, al comparar rastrojos y bosques, ambos a la profundidad de $20-30 \mathrm{~cm}$. Lo mismo ocurre al comparar pastos con rastrojos y pastos con bosques a la misma profundidad, lo que 
CUADRO 3

Abundancia de actinomicetos ( \pm desviación estándar) en células por gramo de suelo, en los diferentes sitios de muestreo con la cobertura rastrojo

TABLE 3

Abundance of Actynomicetes ( \pm standard deviation) in cells per gram of soil, in different sample places with the stubble cover

$\begin{array}{cc}\text { Cobertura Rastrojo } & \text { Abundancia } \times 10^{4}(\mathrm{UFC} / \mathrm{g}) \\ \text { RI } & 2.29 \pm 0.73 \\ \text { RII } & 1.11 \pm 0.26 \\ \text { RIII } & 0.94 \pm 0.45 \\ \text { RIV } & 0.69 \pm 0.22 \\ \text { RV } & 0.95 \pm 0.79\end{array}$

en otras palabras significa que a la profundidad 20-30 cm la abundancia de actinomicetos es igual en las tres coberturas $(\mathrm{P}>0.05)$.

Al comparar al nivel de la profundidad $0-20 \mathrm{~cm}$, se observa que no hay diferencias significativas entre los rastrojos y pastizales, pero que sí existen diferencias entre pastizales y bosques, así como entre rastrojos y bosques $(\mathrm{P}<0.05)$. Igualmente, se encontraron diferencias significativas al comparar las UFC entre los diferentes sitios bajo bosque y rastrojo a las dos profundidades $(0-20$ y $20-30 \mathrm{~cm}$.) $(\mathrm{P}<0.05)$. Para los pastizales no se observó diferencias significativas entre las profundidades de $0-20$ y $20-30 \mathrm{~cm}$ de profundidad $(\mathrm{P}>0.05)$.

En general para las tres coberturas, al igual que para casi todos los sitios de muestreo el mayor promedio de abundancia de actinomicetos se encontró en la profundidad de muestreo $(0-20 \mathrm{~cm})$, siendo mayores los promedios de abundancia reportados en los diferentes sitios de la cobertura bosque (Cuadro 4), lo cual se corrobora con lo mencionado anteriormente sobre los resultados de abundancia total.

\section{Identificación de morfotipos de Actino-} micetos: Con base en las características macro y microscópicas de cada una de las colonias, se identificaron 16 morfotipos de actinomicetos, siguiendo las descripciones morfológicas respectivas de Goodfellow \& Williams (1983). Macroscópicamente, las colonias se caracterizaron por un crecimiento de filamentoso a circular, superficie opaca, consistencia compacta,

CUADRO 4

Abundancia de actinomicetos en los sitios de muestreo bajo dos profundidades

TABLE 4

Abundance of actynomicetes in the sampling sites under two different profundities

\begin{tabular}{|c|c|c|c|}
\hline Cobertura & Sitio de muestreo & Abundancia x $10^{4}(0-20 \mathrm{~cm})$ & Abundancia x $10^{4}(20-30 \mathrm{~cm})$ \\
\hline \multirow{5}{*}{ Bosque } & BI & $1.09 \pm 0.59$ & $0.79 \pm 0.29$ \\
\hline & BII & $1.6 \pm 0.29$ & $0.26 \pm 0.23$ \\
\hline & BIII & $0.41 \pm 0.03$ & $0.16 \pm 0.04$ \\
\hline & BIV & $1.71 \pm 0.24$ & $0.89 \pm 0.62$ \\
\hline & BV & $2.81 \pm 0.48$ & $0.46 \pm 0.35$ \\
\hline \multirow{5}{*}{ Pastizal } & PI & $0.41 \pm 0.17$ & $0.13 \pm 0.07$ \\
\hline & PII & $2.18 \pm 0.62$ & $0.49 \pm 0.43$ \\
\hline & PIII & $0.89 \pm 1.04$ & $0.47 \pm 0.25$ \\
\hline & PIV & $0.65 \pm 0.05$ & $0.78 \pm 0.66$ \\
\hline & PV & $1.09 \pm 0.37$ & $0.78 \pm 0.52$ \\
\hline \multirow{5}{*}{ Rastrojo } & RI & $1.68 \pm 0.49$ & $0.61 \pm 0.24$ \\
\hline & RII & $0.87 \pm 0.13$ & $0.24 \pm 0.13$ \\
\hline & RIII & $0.71 \pm 0.26$ & $0.23 \pm 0.19$ \\
\hline & RIV & $0.61 \pm 0.20$ & $0.08 \pm 0.02$ \\
\hline & RV & $0.66 \pm 0.53$ & $0.29 \pm 0.26$ \\
\hline
\end{tabular}


diámetro entre $0.5-5 \mathrm{~mm}$ y por la producción de exopigmentos difusibles al medio. Estos morfotipos se agruparon en 6 géneros: Streptomyces (morfotipos 1, 3, 4, 5, 11 y 15), Nocardia (morfotipos 2, 2a, 8 y 9), Agromyces (morfotipos 6, 7 y 12), Nocardiopsis (morfotipo 10), Microbispora (morfotipo 13) y Sacharomonospora (morfotipo 14). Streptomyces fue el más representativo con 6 morfotipos, siguiéndole en importancia Nocardia con 4, Agromyces con 3, Nocardiopsis, Microbispora y Sacharomonospora, estos tres últimos representados cada uno por un solo morfotipo.

Diversidad fenotípica de actinomicetos en las tres coberturas vegetales analizadas: Se realizó un análisis de varianza (ANOVA) para determinar una posible heterogeneidad de los índices ecológicos aplicados para cuantificar la diversidad fenotípica de los actinomicetos estudiados. No se observaron diferencias significativas, entre las tres coberturas muestreadas para ninguno de los índices obtenidos (índice de Shannon: $\mathrm{F}=2.66,2$ gdl, $\mathrm{p}=0.1105$; índice de Hill: $\mathrm{F}=2.73,2 \mathrm{gdl}, \mathrm{p}=0.1053$; índice de Margalef: $\mathrm{F}=1.71,2$ gdl, $\mathrm{p}=0.222$; índice de
Simpson: F=1.68, 2 gdl, $\mathrm{p}=0.2266$ ). Como tendencia general se observó que la cobertura con mayor riqueza en cuanto al número de morfotipos fue el bosque, seguida por el rastrojo y el pastizal (Fig. 3).

Asimismo, al interior de los bosques se observó que el sitio BV fue el que reportó un índice de Shannon más elevado, al igual que una riqueza mayor. Respecto a los pastizales, los sitios PII y PV presentaron valores similares de riqueza, diversidad, dominancia y equitatividad, siendo estos mismos sitios los que reportaron mayores abundancias de la comunidad. En cuanto a los rastrojos, los sitios RI y RII reportaron valores similares con una riqueza alta pero con índices de dominancia ligeramente menores (Fig. 3).

Relación de las características físicoquímicas del suelo con la abundancia de actinomicetos: Se realizó un análisis canónico de correspondencia (ACC) para relacionar directamente la composición de la comunidad de actinomicetos con las variables ambientales estimadas. En la Fig. 4, se observa que los vectores correspondientes a las bases (calcio,

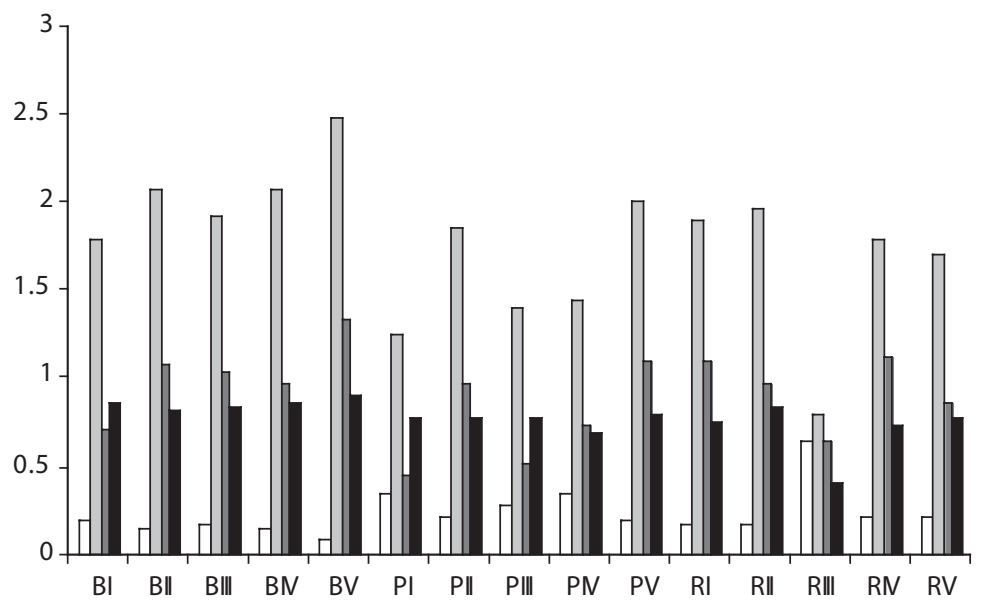

$\square$ Simpson $\square$ Shannon $\square$ Margalef $\square$ Equitatibidad

Fig. 3. Índices de diversidad fenotípica para cada uno de los sitios de muestreo.

Fig. 3. Phenotype diversity indexes for each one of the places sampled. 


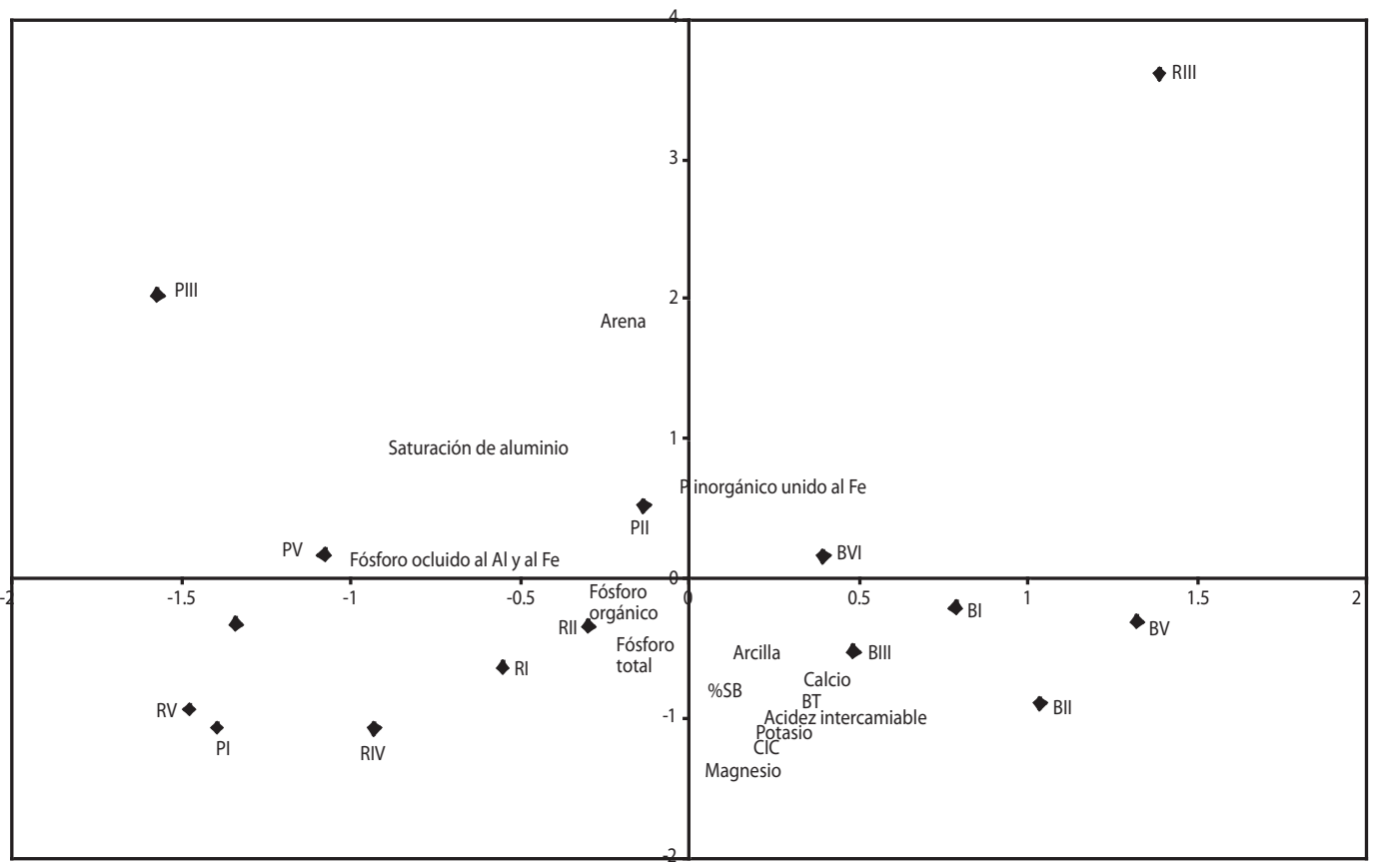

Fig. 4. Representación del análisis canónico de correspondencias que correlaciona las coberturas y las propiedades físicoquímicas de los suelos en el sur del trapecio amazónico.

Fig. 4. Correspondence canonic analysis which correlated the vegetation covers and the physical-chemistry soils properties at the Southern Colombian Amazon.

magnesio, potasio), el porcentaje de saturación de bases, la capacidad de intercambio catiónico y los contenidos de arcilla se ubicaron hacia el sector donde están los suelos bajo bosque, siendo éstos los que presentaron más elevadas correlaciones con estas variables.

Por el contrario, la mayoría de los suelos bajo pastizal presentaron menores valores para estas variables asociadas a la fertilidad. En cuanto a los rastrojos, se observa que se ordenan muy cercanos entre sí y por la posición de los vectores respecto a los sitios I, II, IV y V, se podría concluir que presentan valores intermedios para muchas variables fisico-químicas consideradas. La posición de los sitios (PIII y RIII) en las coberturas pastizal y rastrojo sugiere que el lugar de muestreo III es el más disímil de todas las localidades en las que se realizaron los muestreos.
El ordenamiento de la Fig. 5 muestra la relación entre los morfotipos de actinomicetos y las variables físico-químicas del suelo. Para la mayoría de los morfotipos, su abundancia estuvo directamente relacionada con las mejores condiciones de fertilidad. Este es el caso de $\operatorname{los}$ morfotipos 1, 2, 2a, 7, 12, 13, 14 y 15, donde sus poblaciones se podrían estar favoreciendo en la medida en que son mayores los valores de magnesio, porcentaje de saturación de bases, calcio, la capacidad de intercambio catiónico, el potasio e, incluso, los porcentajes de arcilla.

Resulta muy interesante el caso de los organismos que presentan altos número de unidades formadoras de colonias en condiciones que aparentemente son limitantes para el desarrollo de muchos organismos en general. Esta situación se observa en la Fig. 6 en donde 


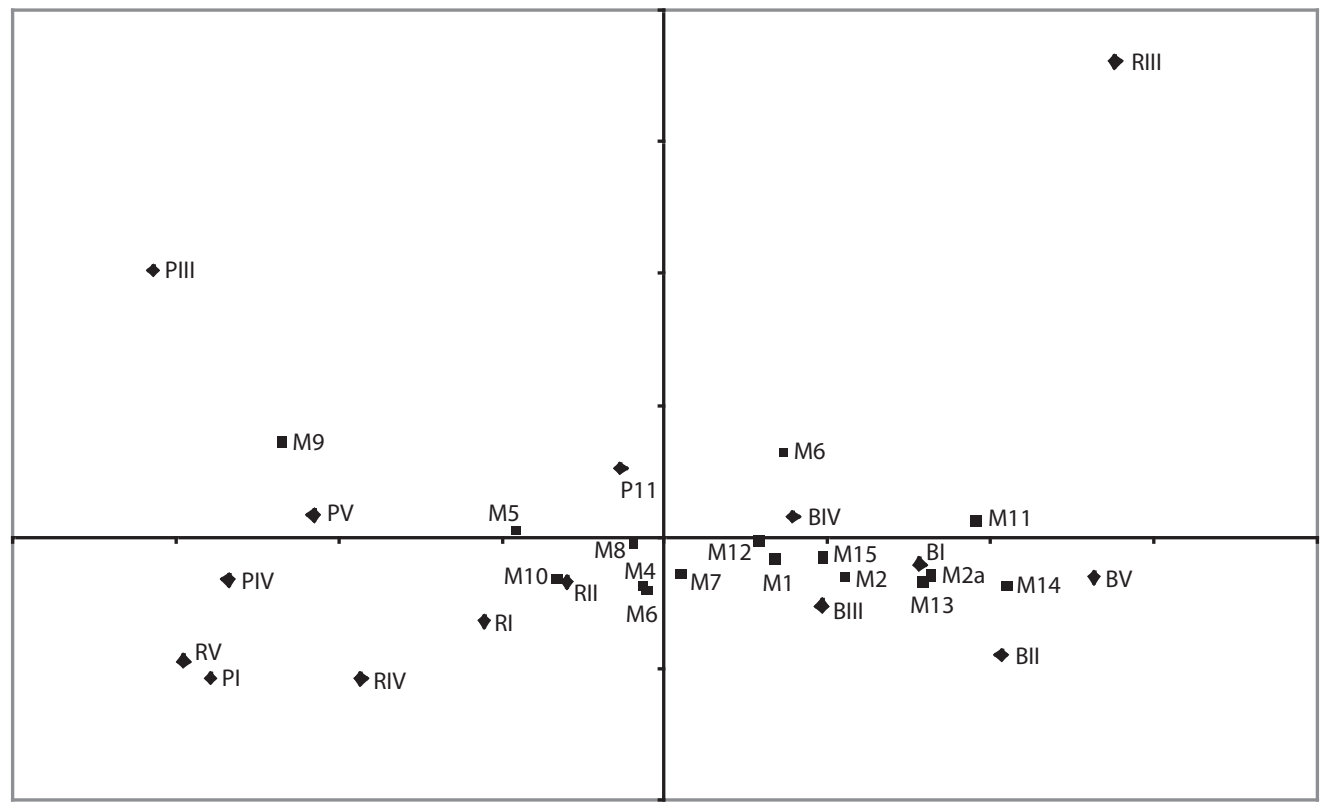

Fig. 5. Representación del análisis canónico de correspondencias que correlaciona los morfotipos de actinomicetos para diferentes coberturas y propiedades físico-químicas en la amazonía colombiana.

Fig. 5. Correspondence canonic analysis which correlated the actynomicete morphotypes for different vegetation covers and the physical-chemistry properties at the Southern Colombian Amazon.

el número de propágulos de los morfotipos 5 y 9 es alto, no obstante están presentes en sitios de menor fertilidad.

Dentro del conjunto de suelos muestreados y ordenados por ACC (Fig. 5), estas particularidades edáficas se observan en suelos bajo pastizales. Estos dos morfotipos parecen tener una mejor expresión fenotípica en suelos cubiertos por pastizales. Sería interesante conocer qué características particulares presentan éstos dos aislamientos que les permiten desarrollarse bajos éstas condiciones. En la Fig. 5 se observa que la mayoría de morfotipos se agrupan en el plano donde se encuentran mejores condiciones de fertilidad, mientras que al observar la Fig. 4, los bosques fueron los que reportaron los mejores valores para estas variables fisico-químicas albergando la mayor riqueza en cuanto a número de morfotipos diferentes de actinomicetos.
Diversidad genética de actinomicetos en suelos amazónicos bajo tres diferentes coberturas: Se extrajo ADN genómico de cada uno de los 16 morfotipos encontrados, a partir de micelio o esporas. Con el protocolo de microextracción se obtuvo ADN sucio y degradado, el cual para algunos aislamientos, no permitió la amplificación exitosa del gen 16S ADNr. Únicamente con la aplicación de pasos adicionales de limpieza, se logró la amplificación. Se obtuvo una mayor concentración de ADN en las extracciones a partir de micelio que de esporas y, a pesar de obtener concentraciones tan bajas para casi todos los morfotipos, éstas fueron suficientes para las reacciones de amplificación por PCR.

Los cebadores F243 ("forward") y R513 GC ("reverse") utilizados para la amplificación del gen $16 \mathrm{~S}$ ADNr en cada uno de los morfotipos, permitieron la obtención de una banda 


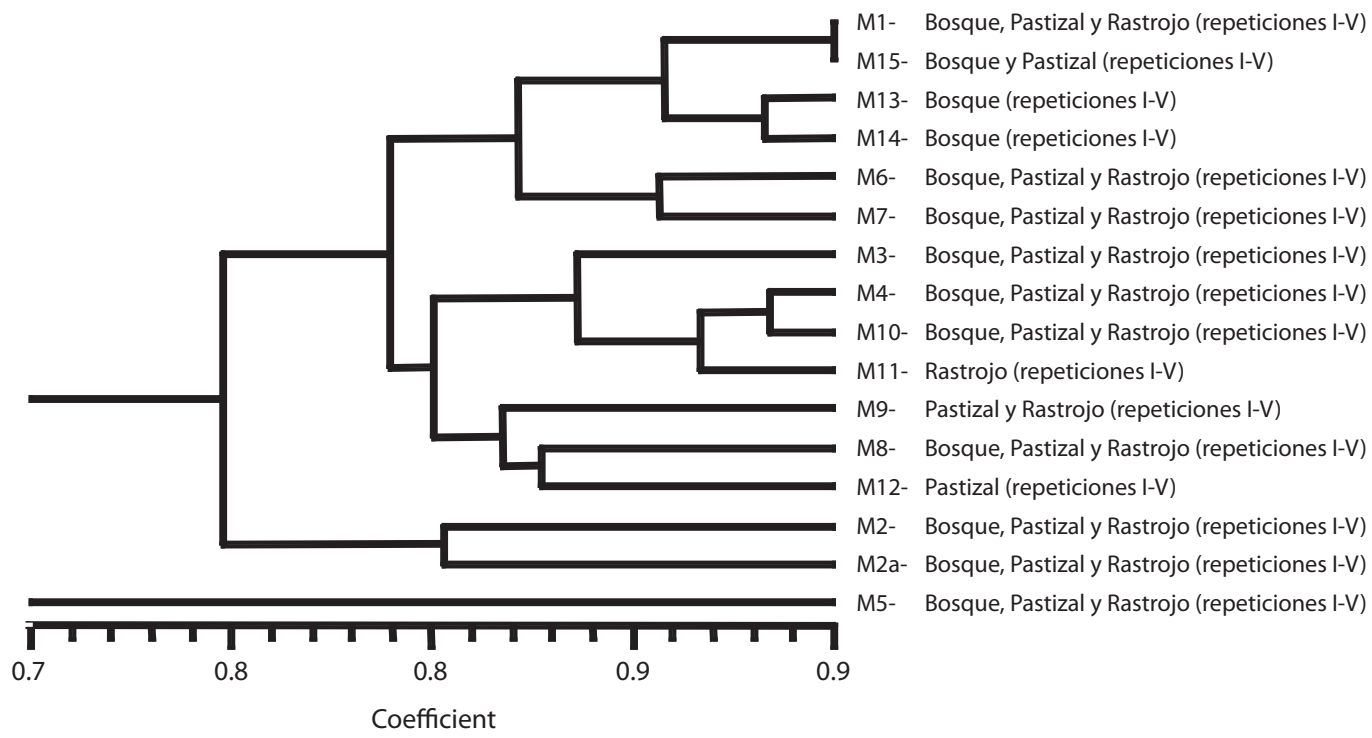

Fig. 6. Relaciones genéticas entre los 16 morfotipos de actinomicetos encontrados en suelos bajo tres coberturas diferentes y repeticiones en la amazonía colombiana basados en perfiles de ARDRA con 7 enzimas de restricción.

Fig. 6. Genetic relationships between 16 actynomicete morphotypes found in soils under three different vegetation covers and repetitions at the Southern Colombian Amazon based on ARDRA profiles by using 7 restriction enzymes.

específica que correspondió al fragmento esperado de $302 \mathrm{pb}$ (Heuer et al. 1997).

Inicialmente el amplificado de $302 \mathrm{pb}$ fue digerido con 8 enzimas de restricción, generándose diferentes patrones para 7 de las 8 enzimas. Con la enzima $A v a \mathrm{I}$, no se encontró sitio de restricción en ninguno de los morfotipos estudiados (Cuadro 5).

Como se observa en la Cuadro 5, las enzimas que mejor discriminaron los morfotipos fueron $H h a \mathrm{I}$ y AluI. Adicionalmente, la enzima HaeIII aportó buena información al posibilitar el análisis de seis bandas, cuatro de las cuales fueron polimórficas. Asimismo, por calidad de bandas observada, la enzima HhaI fue la de mejor comportamiento.

Se construyó una matriz de presenciaausencia considerando simultáneamente los resultados de todas las enzimas y agrupando los aislamientos de actinomicetos según su semejanza genética. Se generó un dendograma a partir de los patrones de ARDRA con los datos de todas las enzimas de restricción usando el coeficiente de Dice y el algoritmo de agrupamiento UPGMA (Fig. 6). Se observó de manera general que todos los morfotipos fueron similares a partir de un coeficiente de Dice de 0.80. Sin embargo, el morfotipo 5 se unió al resto de los morfotipos a 0.74 , siendo el más disímil de todos los morfotipos encontrados.

\section{DISCUSIÓN}

La mayor abundancia de actinomicetos en los suelos de bosque puede relacionarse con la diversidad estructural de la población vegetal que caracteriza a este ecosistema. La información de campo (datos no mostrados) registrada para la cobertura de bosque mostró una alta diversidad de especies vegetales, siendo un indicativo de la variedad de sustratos ofrecidos para la actividad de muchos microorganismos en general, entre ellos los actinomicetos. Torsvik et al. (1996) mencionaron que la alta variabilidad de micro-hábitats genera una mayor 
CUADRO 5

Resultados principales de las enzimas de restricción utilizadas en la caracterización de los morfotipos de actinomicetos

TABLE 5

Main results of the restriction enzyme analysis applied to the characterization of the actynomicetes morphotypes found

$\begin{array}{cccccc}\begin{array}{c}\text { Enzima de } \\ \text { restricción }\end{array} & \begin{array}{c}\mathrm{N}^{\circ} \text { de } \\ \text { fragmentos }\end{array} & \begin{array}{c}\text { Rango de } \\ \text { peso }(\mathrm{pb})\end{array} & \begin{array}{c}\mathrm{N}^{\circ} \text { de bandas } \\ \text { polimórficas }\end{array} & \begin{array}{c}\text { \% de bandas } \\ \text { polimórficas }\end{array} & \begin{array}{c}\text { Bandas } \\ \text { únicas }\end{array} \\ \text { MspI } & 10 & 20-295 & 6 & 60 & 1 \\ \text { HinfI } & 3 & 114-286 & 0 & 0 & - \\ \text { HhaI } & 8 & 40-299 & 8 & 100 & - \\ \text { HaeIII } & 6 & 27-297 & 4 & 66.6 & - \\ \text { AluI } & 2 & 277-297 & 2 & 100 & - \\ \text { RsaI } & 3 & 52-297 & 1 & 33.3 & - \\ \text { TaqI } & 2 & 281-320 & & 50 & -\end{array}$

abundancia de poblaciones microbianas y esta variabilidad puede ligarse directamente con la estructura de la vegetación; además, las características rizosféricas del suelo determinadas en gran medida por la cobertura permiten una acumulación alta y permanente de residuos vegetales a ser descompuestos por este grupo especializado de microorganismos. Todo ello ayuda a entender porqué la cobertura de bosque es la que posee la mayor abundancia de actinomicetos en el sur de la Amazonía colombiana. Los resultados obtenidos muestran como los procesos de destrucción del bosque amazónico, y su transformación en pastizales o rastrojos, reducen la abundancia de actinomicetos de los suelos amazónicos y, por lo tanto, su biodiversidad microbiana.

Según la información de campo, en el sitio de muestreo BV en la cobertura de bosque que fue dónde se determinó el valor promedio más elevado de abundancia de actinomicetos (Cuadro 1), se presentó la mayor capa de horizonte orgánico y hojarasca $(7.5 \mathrm{y} 8 \mathrm{~cm}$, respectivamente) proveniente de troncos descompuestos; igualmente, se observó alta presencia de macrofauna y presencia de manto hifal.

La descomposición de hojarasca, al convertir los residuos vegetales en elementos esenciales, contribuye a una distribución equilibrada de nutrientes en los ecosistemas naturales (Bragazza et al. 2007). Pandey et al.
(2007) determinaron que la producción de hojarasca y su descomposición proporcionan la principal entrada de materia orgánica al suelo, regulando el ciclo de nutrientes en el bosque. La descomposición de los detritos orgánicos proporciona el $70-90 \%$ de los nutrientes anuales que necesita el bosque para crecer y sostener una gran diversidad de poblaciones microbianas, entre éstas la de actinomicetos. La presencia de macrofauna en este sitio de muestreo (BV) estaría relacionada con la degradación de la materia orgánica, debido a que estos macroorganismos descomponen los compuestos orgánicos a formas más simples, para que éstos, a su vez, sean mineralizados por una amplia variedad de microorganismos; actividad que estimularía indirectamente la abundancia y actividad de actinomicetos si se tiene en cuenta que también es función de estos microorganismos la mineralización del carbono y el nitrógeno en los primeros estados de descomposición de la materia orgánica (Sylvia et al. 1998). Todo ello aboga a favor del hecho que los bosques amazónicos primarios deben ser aquellos que posean una mayor abundancia de actinomicetos en sus suelos y que los procesos de intervención humana tienden a disminuir esa abundancia y diversidad.

Aunque no se encontraron diferencias significativas respecto a la abundancia de la comunidad entre las coberturas pastizal y rastrojo, 
para una buena parte de los análisis estadísticos llevados a cabo, los conteos relativamente mayores en suelos bajo pastizal pueden deberse a que las pasturas son aparentemente un tipo de cobertura vegetal muy homogéneo, que, en algunos casos, podría contribuir con una mayor disponibilidad de recursos y condiciones que favorecen el crecimiento de grupos particulares de organismos. Rao et al. (1998) mencionan que los pastos poseen carbohidratos como celulosa, hemicelulosa y compuestos aromáticos, como lignina, cuya digestión total depende de la actividad enzimática de los microorganismos, entre éstos los actinomicetos. Adicionalmente, para el establecimiento de estos pastizales se realizaron prácticas como incorporación de abonos orgánicos, labranza mínima, asociación con leguminosas, entre otros, que pueden haber contribuido a mejorar características del suelo como porosidad, aireación y fertilidad, favoreciendo el establecimiento de actinomicetos.

Asimismo, al interior de los pastizales también se encontraron diferencias (Cuadro 2); de acuerdo con las observaciones de campo (datos no se mostrados) se encontró una alta presencia de lombrices en el lugar de muestreo PII (pastizal de la réplica II), lo que hace pensar que estén ejerciendo un efecto positivo sobre la abundancia y actividad microbiana; ésta estimulación puede deberse a la utilización microbiana de sustancias nutritivas adicionales (productos de secreción y excreción) especialmente compuestos carbonados necesarios para su crecimiento y actividad (Binet et al. 1998). De igual forma, en el sitio PII se observó una asociación del pasto con frijolillo (leguminosa rastrera). Está documentado, el efecto positivo que ejercen las leguminosas sobre la fijación del nitrógeno debido a su asociación con bacterias de la familia Rhizobiaceae, lo que las convierte en un vehículo importante para mejorar la fertilidad de los suelos. Esta capacidad de fijar nitrógeno, puede estar favoreciendo el crecimiento de actinomicetos, ya que este grupo desempeña un papel importante en la nitrificación a pH bajos (Sylvia et al.1998).

Respecto a la cobertura rastrojo la abundancia más baja de actinomicetos puede relacionarse con procesos de sucesión en la vegetación, posteriores a la tumba, tala y quema de bosques, los cuales ocasionan modificaciones en las comunidades biológicas de un ecosistema. Considerando la influencia de la vegetación sobre la formación y estructura del suelo, ésta puede estar alterando las comunidades edáficas nativas.

Sommer et al. (2000) reportan que uno de los principales recursos para el crecimiento vegetal es la reserva de carbón en el suelo. La transformación del bosque para su uso agrícola lleva a una pérdida substancial de la reserva de carbón y de la biomasa en general. Según resultados obtenidos en suelos de la Amazonia occidental de Brasil, los contenidos de carbón orgánico soluble (SOC) después de 1-3 años de barbecho, siguen siendo marcadamente bajos y se necesitarían entre 12-45 años de desarrollo de la vegetación secundaria para que sus contenidos se aproximen a los del bosque primario. Lo anterior hace pensar que los suelos bajo rastrojo no hayan alcanzado una buena reserva de carbón debido a que la mayoría de ellos solo se encuentran entre los 5 y 8 años de sucesión vegetal (datos no se muestran). El carbón que se está generando por descomposición de la hojarasca está siendo consumido rápidamente por plantas pioneras para su crecimiento y colonización. Igualmente la mayoría de las plantas presentes en esta cobertura se encuentran en un estado fisiológico vegetativo que las hace vulnerables al ataque por poblaciones de meso y macrofauna (áfidos, ácaros, arañas, hormigas, termitas, entre otros) quienes consumen los exudados y secreciones ricos en nutrientes presentes en los meristemos apicales (brotes y rebrotes); como consecuencia de esta actividad una gran parte de esta reserva está siendo consumida en la filósfera antes de llegar al suelo y favorecer la actividad de los actinomicetos.

En el caso de la cobertura de rastrojo, el sitio RI fue el que presentó mayor abundancia de actinomicetos (Cuadro 3). La información tomada en campo registró que durante la preparación del terreno para el establecimiento de la chagra, de la cual proviene dicho rastrojo, no se realizó quema, solamente se tumbó el bosque, 
se socoló y se amontonó el material vegetal. Es posible que el hecho de no haber quemado el terreno haya favorecido el mantenimiento de las poblaciones microbianas residentes en este caso, en particular, a la comunidad de actinomicetos. El fuego se ha considerado como un disturbio importante que interrumpe la estructura de un ecosistema, la disponibilidad de sustratos y el medio ambiente físico, influyendo significativamente en la abundancia, actividad y diversidad de las comunidades (Molles \& Manuel 2002).

La abundancia y composición de actinomicetos también fue evaluada bajos dos profundidades de muestreo. Se observan mayores recuentos en la profundidad de $0-20 \mathrm{~cm}$. La determinación de una mayor abundancia de actinomicetos en la profundidad de muestreo menor corrobora lo citado por varios estudios tales como Sylvia et al. (1998) y Campbell (1987), quienes afirmaron que la mayor actividad microbiana se concentra en los primeros centímetros del suelo en donde las raíces de las plantas producen exudados ricos en nutrientes orgánicos como azúcares, aminoácidos, ácidos orgánicos, entre otros, que son muy importantes para el desarrollo de los microorganismos.

Respecto a la caracterización macro y microscópica de morfotipos, se encontró que el género Streptomyces fue el más predominante en los suelos bajo las tres coberturas y las dos profundidades evaluadas. Este género es uno de los mejor reconocidos del orden completo de Actinomycetales debido a su amplia distribución en la naturaleza, especialmente en el suelo y por que alberga a un gran número de los productores más importantes de antibióticos y otros metabolitos secundarios (Wendisch \& Kutzner 1986). Las colonias se caracterizaron por presentar diferentes coloraciones tanto del micelio aéreo como del vegetativo, pasando de amarillo, blanco, crema, rosado hasta terracota-rojizo. Todas formaron micelio aéreo y pigmentos que con periodos prolongados de incubación le dieron el color característico a las colonias maduras. El número y distribución de morfotipos determinados en el presente trabajo concuerdan con lo descrito por Goodfellow \&
Williams (1983) y Xu et al. (1996), quienes reportaron que, en la mayoría de estudios con actinomicetos del suelo, se han aislado cerca de 20 géneros, siendo los Streptomyces los más numerosos, representativos y dominantes dentro de la comunidad.

En cuanto al número de morfotipos de actinomicetos diferentes, medida adicional de diversidad, se observó que la cobertura con mayor riqueza respecto al número de morfotipos fue bosque (16), seguida por rastrojo (14) y por pasto (11). Los morfotipos 1, 3, 4 y 5 , identificados como miembros del género Streptomyces, fueron los más abundantes en las tres coberturas y en las dos profundidades muestreadas.

Sin embargo, se observó que las coberturas rastrojo y pastizal reportaron valores altos de dominancia en comparación con los bosques. Este aumento puede relacionarse con una disminución en la equitatividad de la distribución de las abundancias de los morfotipos de actinomicetos y con la aparición de grupos ecológicamente dominantes, capaces de aprovechar un recurso particular. Lo anterior fue más evidente en los pastizales que en los rastrojos, pues, si bien éstos últimos registraron los menores valores de abundancia total para la comunidad, reportaron mayores valores de riqueza, comparable con los bosques.

Estos resultados coinciden con lo reportado en la literatura según lo cual se presenta una disminución de la diversidad relacionada con los procesos de perturbación. Torsvik et al. (1996) mencionan que las modificaciones en la vegetación natural, así como el manejo de cultivos, inducen a una sucesión e inestabilidad de las poblaciones microbianas. Al igual que en la vegetación, las etapas primarias de sucesión de las comunidades microbianas estarían caracterizadas por la dominancia de unos pocos organismos y una baja diversidad. Comparativamente, las comunidades maduras se caracterizan por una mayor diversidad, generada por la equitatividad de los diferentes grupos presentes.

Es importante destacar que la variación de los índices de diversidad y la abundancia 
total de la comunidad de actinomicetos entre los diferentes sitios de muestreo (replicas I-V) muestra el efecto de las condiciones o características particulares de las tres coberturas. Variables como el espesor del horizonte orgánico, capa de hojarasca, presencia de meso y macrofauna, problemas de drenaje y estructura de la vegetación entre otras, pueden influir sobre las diferencias observadas al interior de cada cobertura.

\section{Caracterización molecular ARDRA}

En la caracterización molecular mediante el análisis de ARDRA de la comunidad cultivable de actinomicetos, se observó que de las 7 enzimas de restricción utilizadas, la enzima $H h a$ I fue la de mejor comportamiento, y junto con la enzima Alu I, la que generó el mayor número de bandas polimórficas Asimismo, la enzima HaeIII aportó buena información al posibilitar el análisis de 6 bandas, 4 de las cuales fueron polimórficas (Cuadro 5). Estos resultados concuerdan con lo encontrado por Sessitsch et al. (2002), quienes determinaron en un análisis de T-RFLP en suelos rizosféricos de papa, que las enzimas de restricción HhaI y HaeIII fueron las que produjeron altos números de patrones de restricción en las muestras evaluadas.

Respecto a la enzima $M s p$ I fue la única que generó una banda cuya presencia discriminó el morfotipo 6. Por otro lado, la enzima Hinfl no permitió la discriminación de ninguno de los aislamientos pues generó solo bandas monomórficas, sugiriendo la presencia de sitios altamente conservados para todos los morfotipos evaluados. Estos resultados son contrarios a lo encontrado por Corredor (2000), quién determinó que la enzima Hinfl fue la que generó mayor número de patrones diferentes para los aislamientos obtenidos, logrando separar los géneros Microbispora y Streptosporangium de los morfotipos correspondientes al género Streptomyces. Los resultados encontrados en la presente investigación podrían indicar que los morfotipos presentes en suelos amazónicos constituyen grupos diferentes a los reportados en suelos de la franja cafetera del Quíndio.
En los análisis canónico de correspondencia, en los cuales se relacionó la abundancia (UFC/g) para cada uno de los morfotipos con algunos parámetros físico-químicos del suelo (Fig. 5), se observó que el morfotipo 5, identificado como Streptomyces sp. 4, fue el que reportó mayor número de propágulos en suelos bajo la cobertura pasto en condiciones aparentemente limitantes para el desarrollo de muchos microorganismos, en general, como fueron contenidos altos de arena, saturación tóxica por aluminio y fósforo inorgánico unido al hierro, características que disminuyen el aporte de nutrientes al suelo. Lo anterior podría sugerir que ciertos rasgos genéticos le estén confiriendo a este morfotipo algunas características especiales para su adaptación y crecimiento activo bajo estas condiciones.

Weidner et al. (1996) analizaron comunidades microbianas asociadas a pastizales (Halophila stipulacea) por T-RFLP postulando que valores de semejanza superiores al 95\% entre morfotipos permite agruparlos dentro del mismo biotipo. Considerando como criterio de identidad este porcentaje, la semejanza del 98\% entre los morfotipos M1 y M15, ambos asignados por sus características microscópicas como miembros del género Streptomyces, permite asignarlos a un mismo biotipo, a pesar que, microscópicamente, mostraron diferencias en características como el color del micelio áereo y del sustrato, forma, consistencia y producción de exopigmentos.

Es posible que las condiciones selectivas impuestas por el medio de cultivo (AA), hayan influenciado la expresión de esas características macroscópicas en cada aislamiento. Wendisch \& Kutzner (1986) determinaron que la composición del medio tiene una fuerte influencia sobre el color del micelio aéreo debido a que el pigmento producido por el micelio del sustrato puede difundirse dentro de la hifa aérea y modificar su color verdadero. A diferencia de los resultados obtenidos con los morfotipos 1 y 15, los análisis de ARDRA fueron suficientes para separar morfotipos dentro del mismo género, cada una por un único patrón. Es decir, se logró la diferenciación entre los morfotipos 
3, 5 y 11 asignados por sus características macro y microscópicas como Streptomyces, siendo el morfotipo 3 el más disímil.

Igualmente en la Fig. 6, se observo que los morfotipos 2 y 2 a identificados como miembros del género Nocardia sp1 y sp 2, respectivamente, se encuentran agrupados con una semejanza del $87 \%$. Estos dos morfotipos macroscópicamente divergieron en pocas características, por lo que, inicialmente, se agruparon como un mismo morfotipo. Sin embargo, con procedimientos de incubación prolongados, estos aislamientos empezaron a presentar rasgos diferentes en sus características macroscópicas, pero no microscópicamente. Si se considera el porcentaje de similitud superior al $95 \%$ como referente de pertenencia a un mismo biotipo, los morfotipos 2 y 2 a corresponderían a biotipos diferentes y estas diferencias moleculares estarían relacionadas con los diferentes operones del gen $\mathrm{ADNr}$ dentro de cada uno.

Asimismo, los morfotipos 8 y 9 identificados, como pertenecientes al género Nocardia, también pueden considerarse como biotipos diferentes, pues se relacionan el uno con el otro en una semejanza del $87 \%$, aproximadamente. Algo similar se observa con los morfotipos 6 y 7 asignados como Agromyces, que presentan una semejanza del $92 \%$.

Los morfotipos 4 y 10 identificados como miembros de los géneros Streptomyces y Nocardiopsis, respectivamente, se agruparon a un nivel de semejanza del $96 \%$, indicando posiblemente que representan el mismo biotipo. Respecto a las características macroscópicas, estos morfotipos fueron bastante diferentes. Sin embargo, microscópicamente la ausencia de estructuras como cadenas de esporas y bucles en el morfotipo 10 no permitió asignarlo como un miembro del género Streptomyces. Kroppenstedt (1986), menciona que existe un alto grado de sobrelapamiento morfológico entre taxas filogenéticamente relacionados como son Nocardiopsis, Streptomyces y Nocardia, los cuales comparten semejanzas en sus estructuras morfológicas como son: conidias o artrosporas producidas sobre el micelio aéreo. Estos mismos autores mencionan que en estudios sobre secuenciación del gen 16S RNAr, Nocardiopsis ocupa una posición filogenética entre Microtetraspora y Streptomyces llevando a la asignación equivocada de muchos miembros de Streptomyces como pertenecientes a Nocardiopsis.

Los géneros Microbispora y Sacharomonospora, cada uno representado por un solo morfotipo (13 y 14, respectivamente) se relacionaron muy cercanamente con una semejanza del 94\%. Estos géneros reportaron sus mayores abundancias en bosque, seguida de rastrojo y sin ninguna presencia en pastizales. Es posible que estas coberturas estén proporcionando elementos comunes como sustratos nutritivos o la capacidad para explotar recursos similares, confiriéndoles ciertas características que permitan su agrupamiento a nivel molecular.

Se realizó una búsqueda en la base de datos NCBI (National Centre for Biothecnology Information) de las secuencias para los genes $16 \mathrm{~S}$ ribosomales más representativas por especies dentro de los 6 géneros de actinomicetos encontrados, llevando a cabo una simulación del alineamiento de los cebadores (F243 y R513GC) con las secuencias seleccionadas por medio del programa primer 3 y una simulación de la restricción con las enzimas (Hinfl, HhaI, HaeIII, AluI, RsaI y TaqI) con el programa redbase.

Para el caso del género Streptomyces, se seleccionaron las secuencias de las especies $S$. coelicolor y S. albus; para el género Nocardia, la secuencia de $N$. pseudobrasilensis; para el género Agromyces, la secuencia de la especie A. fucozus y para los géneros Sacharomonospora y Microbispora las secuencias de las especies $S$. glauca y M. rosea, respectivamente.

La presencia de bandas comunes en el patrón obtenido mediante el corte con las enzimas Hinfl, HaeIII, RsaI y TaqI en el presente estudio sugieren la presencia de sitios de restricción conservados para todos los géneros de actinomicetos evaluados. La simulación de corte sobre las secuencias seleccionadas en la base de datos con estas enzimas, mostró la presencia de dos bandas comunes de 176 y 112 pb con Hinfl, 85 y 61pb con HaeIII, 299 pb con $R s a \mathrm{I}$ y $280 \mathrm{pb}$ con $T a q \mathrm{I}$. 
Estos fragmentos tienen pesos bastante aproximados a los patrones comunes observados en los análisis de restricción con todos los aislamientos (Cuadro 5). Es importante mencionar que en los ensayos de restricción realizados con la enzima AvaI, no se encontró sitio de restricción para ninguno de los 16 morfotipos evaluados, mientras que en los ensayos de simulación, la mayoría de especies reportaron uno y dos patrones. Sin embargo, los patrones esperados y los obtenidos permiten suponer que los aislamientos reportados en el presente estudio, no corresponden con especies actualmente reportadas en las bases de datos, de modo que podría pensarse que los actinomicetos encontrados en suelos del Sur del Trapecio constituyen una fuente de nuevas especies.

Zhou et al. (2002) menciona que la mayoría de secuencias de las especies bacterianas cultivadas que se encuentran registradas en las bases de datos, no son fiel representación de la diversidad total microbiana de un ambiente dado; por lo tanto, la comprensión de su diversidad genética estaría condicionada por la necesidad de aislar cultivos puros de microorganismos. Sin embargo, aun dentro de la fracción cultivable de bacterias obtener microorganismos que sean representativos de la diversidad existente puede ser difícil como resultado del sesgo inherente a la metodología de aislamiento.

De acuerdo a todo lo anterior se puede decir que la región amplificada de 302 pb está bastante conservada en todos los morfotipos y que la presencia de regiones variables no pudo ser evidenciada del todo con las enzimas de restricción utilizadas. Sin embargo, es necesario precisar que para la mayoría de las enzimas no se presentó una correspondencia del $100 \%$ entre los patrones esperados (a partir de los ensayos de simulación en las bases de datos NCBI) y los patrones generados en los análisis de ARDRA, haciendo imposible su identificación a nivel de especie.

Una posible explicación para estos hallazgos sería la variación entre las secuencias de los diferentes operones de los genes ribosomales en un mismo organismo, llevando a la modificación de los patrones de ARDRA. Gürtler \& Stanisich (1996) reportan que la mayoría de especies gram positivas y negativas estudiadas portan copias múltiples del operon RNAr, y en muchas especies este número puede ser mayor a 10 , generando cambios en los patrones de restricción esperados. Igualmente podría suceder que las presiones selectivas del medio de cultivo conlleven a una acumulación de mutaciones seleccionadas negativamente en la naturaleza que modifiquen los patrones de restricción esperados. Ueda et al. (1999) sugieren dos mecanismos causantes de heterogeneidad de los genes 16S rRNA dentro de un mismo organismo: sustitución de bases durante la replicación del ADN y mecanismos de transferencia horizontal de genes mediados por plásmidos conjugativos, durante procesos evolutivos del genoma.

Sea como fuere, este es un primer estudio que muestra la extraordinaria importancia de la aplicación de diversos tipos de herramientas analíticas, incluyendo las moleculares, para el estudio de la composición y la dinámica de microorganismos en suelos amazónicos.

\section{AGRADECIMIENTOS}

Los autores expresan sus agradecimientos a los colonos y comunidades indígenas del Sur del Trapecio Amazónico Colombiano por haber permitido el trabajo de campo. A María Mercedes Zambrano y a Camilo Flores por la asesoría y apoyo técnico.

\section{RESUMEN}

Los actinomicetos son importantes en la sostenibilidad de sistemas naturales. Su diversidad fue evaluada en suelos de bosque, pastizal y rastrojo, y dos profundidades en el Sur del Trapecio Amazónico Colombiano. Se analizaron suelos de cinco repeticiones por cobertura para un total de 15 unidades. Se tomaron seis muestras en cada unidad y dos profundidades, para un total de 30 . Los actinomicetos cultivables se determinaron por recuento en placa, se extrajo ADN, se amplificó el gen ADNr 16s y su diversidad genética se estimó por ARDRA. Hubo diferencias de abundancia entre coberturas y profundidades, relacionadas con 
la vegetación, presencia de lombrices, macrofauna, altos niveles de materia orgánica, y bases totales. Se obtuvieron valores de diversidad fenotípica similares para las tres coberturas, pero los bosques son más diversos. Se identificaron 16 morfotipos, agrupados en séis géneros, siendo Streptomyces el más abundante. La heterogeneidad de los patrones ARDRA no permitió la asignación de especies, reflejándose variaciones en las secuencias de diferentes operones $\mathrm{ADNr}$ 16s en un mismo organismo. Las perturbaciones en la cobertura influyen sobre los actinomicetos, generando cambios en su abundancia y diversidad. Su importancia ecológica permite proponerlos como indicadores biológicos de alteración del paisaje.

Palabras claves: actinomicetos, bosque, pastizal, rastrojo, gen ADNr 16S, ARDRA, diversidad fenotipica y genetica, Amazonía colombiana.

\section{REFERENCIAS}

Albarracín, V.H., M.J. Amoroso \& C.M. Abate. 2005. Isolation and characterization of indigenous Koper-resistant actinomycete strains. Chem. Erde. 65: 145-156.

Bragazzaa, L., C. Siffia \& R. Gerdola. 2007. Mass loss and nutrient release during litter decay in peatland: the role of microbial adaptability to litter chemistry. Soil Biol. Biochem. 39: 257-267.

Benzecrí, J. P. 1976. L’Analyse des Données. I. La taxinomie. L'Analyse des Données. II. L' Analyse des correspondances. Dunod. París, Francia.

Binet, F., L. Fayolle \& M. Pussard. 1998. Significance of earthworms in stimulating soil microbial activity. Biol. Fertil. Soils 27: 79-84.

Borneman, J \& E. Triplett. 1997. Molecular microbial diversity in soils from Eastern Amazonia: Evidence for unusual microorganisms and microbial population shifts associated with deforestation. Appl. Environ. Microbiol. 63: 2647-2653.

Boudemagh, A., M. Kitouni, F. Boughachiche, H. Hamdiken, L. Oulmi, S. Reghioua, H. Zerizar, A. Couble, D. Mouniee, A. Boulahroug \& P. Boiron. 2005. Isolation and molecular identification of actinomycete microflora, of some Saharian soils of South East Algeria (Biskra, EL-Ouded and Ourgla) study of antifungal activity of isolated strains. J. Mycolog. Med. 15: 39-44.

Campbell, R. 1987. Ecología microbiana. LIMUSA. Ciudad de México. México.

Cardona, G.I., A.L. Arcos \& U.G. Murcia. 2005. Abundancia de actinomicetos y micorrizas arbusculares en paisajes fragmentados de la Amazonía Colombiana. Agron. Colomb. 23: 317-326.

Cordier, B. 1965. Sur 1'analyse factorielle des correspondences. PhD Thesis, Rennes, Francia.

Corredor, P. 2000. Estructura de la comunidad edáfica del género Streptomyces en bosques relictuales y agroecosistemas del Quindío (Andes Colombianos). Tesis de Biología. Facultad de Ciencias, Universidad Nacional de Colombia. Cundinamarca, Bogotá, Colombia.

Cuadras, C. 1991. Métodos de análisis multivariante. Promociones y Publicaciones Universitarias, SA. Barcelona, Barcelona, España.

De La Torre, L. 1993. Distribución y actividad de los microorganismos, p. 123-189. En Instituto Geográfico Agustín Codazzi. Aspectos ambientales para el ordenamiento territorial del occidente del departamento de Caquetá. Tercer mundo. Bogotá, Cundinamarca, Colombia.

Duncan, D. B. 1955. Multiple range and multiple F tests. Biometrics 11: 1-42.

Goodfellow, M \& S.T. Williams. 1983. Ecology of Actinomycetes. Ann. Rev. Microbial. 37: 189-216.

Gürtler, V \& V. A. Stanisich. 1996. New approaches to typing and identification of bacteria using the 16S23S ADNr spacer region. Microbiology 142: 3-16

Heuer, H., M. Krsek., P. Baker., K. Smalla \& E. Wellington. 1997. Analysis of Actinomycete communities by specific amplification of genes encoding 16S rRNA and gel-electrophoretic separation in denaturing gradients. Appl. Environ. Microbiol. 63: 3233-3241.

Hua-Li, X., L. Qi-Ren \& J. Cheng-Lin. 1996. Diversity of soil Actinomycetes in Yunnan China. Appl. Environ. Microbiol. 6: 244-248.

Instituto Geográfico Agustín Codazzi (IGAC). 1996. Suelos de Colombia; origen, evolución, clasificación, distribución y uso. Canal Ramírez Antares Ltda. Bogotá, Cundinamarca, Colombia.

Instituto Geográfico Agustín Codazzi. 1997. Zonificación Ambiental para el Plan Modelo Colombo-Brasilero (Eje Apaporis-Tabatinga: PAT). Canal Ramírez Antares Ltda. Bogotá, Cundinamarca, Colombia.

Kennedy, A. \& K. Smith. 1995. Soil microbial diversity and the sustainability of agricultural soils. Plant Soil 170: 75-86. 
Keuls, M. 1952. The use of the "studentized range" in connection with an analysis of variante. Euphytica 1: $112-122$

Kroppenstedt R., M. 1986. The genus Nocardiopsis, p. 1140-1156. In P. M. Starr, H. Stolp, G. H. Trüper, A. Balows \& G.H. Schlegel. The prokaryotes. A handbook on habitats, isolation and identification of bacteria. Berlin Heidelberg. Nueva York, Nueva York, EEUU.

Lleonart, J. 1978. La comunitat epibentónica del banc Canario-Sahariá: tipificació i cartografia mitjancant l'analisi de dades i comentaris crítics sobre la metodología. PhD Thesis. Facultat de Biología. Universitat de Barcelona, Barcelona, España.

Magurran, A. E. 1988 Ecological diversity and its measurement. Princeton University Press. Princeton, New Jersey, EEUU.

Hill, M. O. 1973. Diversity and evenness: a unifying notation and its consequences. Ecology 54: 423-432.

Margalef, R. 1972. Interpretaciones no estrictamente estadísticas de la representación de entidades biológicas en un espacio multifactorial. Invest. Pesq. 36: 183190.

Molles, J.R. \& C. Manuel. 2002. Ecology. Concepts and applications. McGraw-Hill Higher Education. Universidad de Nuevo México, Albuquerque, EEUU.

Nei, M. 1987. Molecular evolutionary genetics. Columbia University Press. Nueva York, Nueva York, EEUU.

Newman, D. 1939. The distribution of range in samples from a normal population, expressed in terms of an independent estimate of standard deviation. Biometrika 31: 20-30.

Pandey, R.R., G. Sharma., S.K. Tripathi \& A.K. Singh. 2007. Litterfall, litter decomposition and nutrient dynamics in a subtropical natural oak forest and managed plantations in Northeastern India. For. Ecol. Manage. 240: 96-104.

Rao, I. M., P.C. Kerridge \& M.C.M. Macedo. 1998. Requerimientos nutricionales y adaptación a los suelos ácidos de especies de Brachiaria, p. 47-62. En CIAT. Brachiaria: Biología, agronomía y mejoramiento. Cali, Valle del Cauca, Colombia.

Rohlf, F.J. 1998. Numerical taxonomy and multivariate analysis system. Versión 2.0. Exeter, Setauket, Nueva York, EEUU.

Ruiz-García, M, A. Murillo, C. Corrales, N. Romero-Aleán \& D. Alvarez-Prada. 2007. Genética de poblaciones Amazónicas: La historia evolutiva del jaguar, ocelote, delfín rosado, mono lanudo y piurí reconstruida a partir de sus genes. Animal Biodiversity and Conservation 30: 115-130.

Shannon, C.E. 1948. A mathematical theory of communication. BSTJ. 27: 379-423.

Scheffé, H. 1959. The analysis of variance. Wiley, Nueva York, Nueva York, EEUU.

Sessitsch, A., R. Birgit., P. Ulrike \& E. Wilhelm. 2002. Cultivation-independent population analysis of bacteria endophytes in three potato varieties based on eubacterial and Actinomycetes-specific PCR of $16 \mathrm{~S}$ rRNA genes. FEMS Microbiol. Ecol. 39: 23-32.

Simpson, E. H. 1949. Measurement of diversity. Nature 163: 688

Sylvia, D., J. Fuhrmann., P. Hartel \& D. Zuberer. 1998. Principles and applications of soil microbiology. Prentice Hall, New Jersey. Nueva York, EEUU.

Sommer, R., M. Denich \& P. Vlek. 2000. Carbon storage and root penetration in deep soils under small-farmer land-use systems in the Eastern Amazon region, Brazil. Plant Soil 219: 231-241.

Torsvik, Y., R. Sorheim \& J. Goksoyr. 1996. Total bacterial diversity in soil and sediments communities-a review. J. Indust. Microbiol. 17: 170-178.

Tukey, J. W. 1953. The problem of multiple comparisons. The problem of multiple comparisions. Department of Statistics, Princeton University. Chapman \& Hall, Nueva York. Nueva York, EEUU.

Ueda, K., T.K. Seki., T. Kudo., T. Yoshida \& M. Kataoka. 1999. Two distinct mechanisms cause heterogeneity of 16S rRNA. J. Bacteriol. 181: 78-82.

Vanderlei Anselmi, R. 2004. Amazonia. Uma abordagem multidisciplinary. Icone Editora Ltda. Sao Pablo, Brasil.

Waksman, S. 1967. The Actinomycetes, a summary of current knowledge. The Ronald Press Company, Nueva York. Nueva York, EEUU.

Weidner, S., W. Arnold \& A. Pühler. 1996. Diversity of uncultured microorganisms associated with the seagrass Halophila stipulacea estimated by restriction fragment length polymorphism analysis of PCR-Amplified 16S rRNA genes. Appl. Environ. Microbiol. 62: 766-771.

Wendish-Korn, F. \& J.H. Kutzner. 1986. The family Streptomycetaceae, p. 922-994. In P.M. Starr., H. Stolp., 
G. H. Trüper., A. Balows \& G.H. Schlegel. The prokaryotes. A handbook on habitats, isolation and identification of bacteria. Berlin Heidelberg, Nueva York. Nueva York, EEUU.

Williams, E.J. 1952. Use of scores for the analysis of association in contingency tables. Biometrika 39: 274-289.

Williams, S.T., S. Lanning \& E. Wellington. 1984. Ecology of Actinomycetes, p. 45-53, In M. Goodfellow., M. Mordarski \& S.T. Williams. The biology of the Actinomycetes. Academic Press. Londres, Inglaterra.
Xu, L-H., Q-R. Li \& C-L. Jiang. 1996. Diversity of aquatic Actinomycetes in lakes of the Middle Plateau, Yunnan, China. Appl. Environ. Microbiol. 62: 249-253.

Zhou, J., B. Xia, D. Treves, L. Wu, T. Marsh, R. O'neill, A. Palumbo \& J. Tiedje. 2002. Spatial and resource factors influencing high microbial diversity in soil. Appl. Environ. Microbiol. 68: 326-334.

Zuart, J.L. 1998. Caracterización bioquímica y molecular de la judía (Phaseolus vulgaris L.). Trabajo de tesis. Escuela Técnica Superior de Ingenieros Agrónomos. Universidad Politécnica de Madrid, Madrid, España. 
